\title{
Twenty-four hour insulin secretion and beta cell NEFA oxidation in type 2 diabetic, morbidly obese patients before and after bariatric surgery
}

\author{
S. Salinari • A. Bertuzzi • A. Iaconelli • M. Manco • \\ G. Mingrone
}

Received: 2 January 2008 / Accepted: 12 March 2008 / Published online: 6 May 2008

(C) Springer-Verlag 2008

\begin{abstract}
Aims/hypothesis We have previously demonstrated that type 2 diabetes resolves after bariatric surgery. To study the role of NEFA in the prompt normalisation of beta cell glucose sensitivity, insulin secretion and beta cell glucose and lipid metabolism were investigated by a model of nutrient-stimulated insulin secretion using a multiple-meal test.

Methods Hourly glucose, C-peptide and NEFA were measured in nine morbidly obese, type 2 diabetic patients before and 1 week after bariatric surgery and in six matched healthy volunteers over $24 \mathrm{~h}$. A mathematical model of glucose-NEFA comodulation of insulin secretion rate (ISR) was used to compute ISR and $\beta$-oxidation. Insulin sensitivity was measured by an OGTT minimal model.

Results Beta cell sensitivity to glucose and NEFA was doubled after surgery, while the $24 \mathrm{~h}$ insulin secretion decreased from $277.1 \pm 144.4$ to $198.0 \pm 107.6 \mathrm{nmol} / \mathrm{m}^{2}$ $(p<0.02)$. Insulin sensitivity was restored. The $\beta$-oxidation
\end{abstract}

S. Salinari $(\bowtie)$

Department of Systems Analysis and Informatics,

University of Rome 'La Sapienza',

Via Ariosto 25,

00185 Rome, Italy

e-mail: salinari@dis.uniroma1.it

A. Bertuzzi

Institute of Systems Analysis and Computer Science, CNR,

Rome, Italy

A. Iaconelli $\cdot$ G. Mingrone

Institute of Internal Medicine, Catholic University,

School of Medicine,

Rome, Italy

M. Manco

Liver Unit, Bambino Gesù Hospital and Research Institute,

Rome, Italy rate of beta cells was completely normalised (from $0.032 \pm$ $0.012 \times 10^{-12}$ to $0.103 \pm 0.031 \times 10^{-12} \mathrm{mmol} / \mathrm{min}$ per cell, $p<0.005)$. The best predictor of beta cell function improvement was the duration of diabetes.

Conclusions/interpretation Bariatric surgery in type 2 diabetes restores $\beta$-oxidation in beta cells, doubles glucose-NEFA sensitivity and reverses diabetes. It is likely that ISR is reduced to match insulin-sensitivity normalisation, in spite of no significant reduction in NEFA levels. We hypothesise that insulin sensitivity normalisation might appear as a consequence of nutrient exclusion from proximal intestinal transit, and that secondarily the need for insulin secretion diminishes. The insulin sensitivity increase is much higher than usually obtained by insulinsensitising agents and is independent of weight changes.

Keywords Bariatric surgery - Beta cell secretion · Mathematical model · Type 2 diabetes mellitus

$\begin{array}{ll}\text { Abbreviations } \\ \text { ADA } & \text { American Diabetes Association } \\ \text { BPD } & \text { bilio-pancreatic diversion } \\ \text { CPT-1 } & \text { carnitine palmitoyltransferase 1 } \\ \text { DAG } & \text { diacylglycerol } \\ \text { FFM } & \text { fat-free mass } \\ \text { ISR } & \text { insulin secretion rate } \\ \text { LC-CoA } & \text { long-chain acyl-CoA } \\ \text { TBW } & \text { total body water }\end{array}$

\section{Introduction}

Fat mass and cell size in both subcutaneous and intraabdominal fat tissues, as well as the rate of lipolysis, are much increased in obese individuals compared with 
normal-weight individuals [1] leading to the rise of circulating NEFA. As a consequence of adipose tissue insulin resistance, this enhanced lipolysis is unresponsive to hyperinsulinaemia [2-5] and, in turn, induces insulin resistance in other tissues by increasing the plasma NEFA concentration. In fact, high levels of plasma NEFA also cause hepatic and skeletal muscle insulin resistance in healthy individuals [2-5].

Adipose tissue insulin resistance seems to play a relevant role in the development of type 2 diabetes mellitus [2-6]. An elevated lipid turnover rate has been found to precede the development of type 2 diabetes in individuals with a family history of diabetes [7-9]. Fatty acids amplify glucose-stimulated insulin secretion, thus playing a central role in the mechanism of beta cell compensation for insulin resistance [10]. However, high NEFA levels, in a range close to those observed in obesity, impair insulin secretion in the offspring of both diabetic parents [11]. Accordingly, short-term treatment with the antilipolytic agent acipimox improves insulin sensitivity and secretion in normal glucose-tolerant nondiabetic individuals with a strong family history of type 2 diabetes [12].

In the long term, morbidly obese individuals undergoing malabsorptive bariatric surgery (bilio-pancreatic diversion [BPD]) show a large reduction of plasma NEFA concentration [13-16]. In type 2 diabetic patients who underwent BPD, the beta cell glucose sensitivity was restored in about 2 years [17]. However, BPD results in an early reversibility of type 2 diabetes by normalising peripheral insulin sensitivity and enhancing beta cell glucose sensitivity long before a significant weight loss takes place [18].

We have recently demonstrated [19] that the inclusion of plasma NEFA concentration as a comodulator of circulating glucose levels in the insulin secretion process permits an explanation, at least in part, of the potentiation factor used in previous mathematical models $[20,21]$ to account for control factors other than glucose after either mixed meals and/or oral glucose load. The model describes in a simplified way some of the interactions between glucose and fatty acid metabolism in nutrient-secretion coupling $[10,22,23]$.

To investigate the role of NEFA in the prompt normalisation of beta cell glucose sensitivity after BPD, previously observed by using an OGTT [18], insulin secretion and beta cell glucose and lipid metabolism were investigated in the present study by a model of nutrient-stimulated insulin secretion [19] using the multiple-meal test. To this purpose, nine type 2 diabetic patients and six healthy controls matched for age and sex were studied over $24 \mathrm{~h}$ in a calorimetry chamber.

\section{Methods}

Patients and controls Nine morbidly obese (BMI $=46.2 \pm$ $7.7 \mathrm{~kg} / \mathrm{m}^{2}[$ mean $\pm \mathrm{SD}]$ and fat-free mass $[\mathrm{FFM}]=84.6 \pm$ $16.6 \mathrm{~kg}$ ) type 2 diabetic patients and six sex- and agematched healthy volunteers $\left(B M I=24.4 \pm 1.1 \mathrm{~kg} / \mathrm{m}^{2}\right)$ were studied. The patients were all characterised as having type 2 diabetes according to the criteria established by the American Diabetes Association (ADA) [24]. $\mathrm{HbA}_{1 \mathrm{c}}$ was $6.0-9.5 \%$.

Study protocol All individuals were randomly assigned to the $24 \mathrm{~h}$ metabolic study or to the OGTT either at baseline and 7-9 days after bariatric surgery. The two tests were performed at an interval of 24-48 h.

At the time of the baseline study, all individuals were on a diet with the following average composition: $60 \%$ carbohydrate, $30 \%$ fat and $10 \%$ protein $(\geq 1 \mathrm{~g} / \mathrm{kg}$ body weight). This dietary regimen was maintained for 1 week before the study. All patients received the same parenteral nutrition regimen (about 7,100 kJ/day) during the first 6 days after surgery, then they were on free diet. For the basal study, each individual spent $24 \mathrm{~h}$ (starting at 08:00 hours) on the metabolic ward. Four meals were administered in the calorimetric chamber for a total energy intake of $104.5 \mathrm{~kJ}$ $(25 \mathrm{kcal}) / \mathrm{kg}$ FFM: $16.4 \%$ at breakfast at 09:00 hours, 36\% at lunch between 12:00 and 13:00 hours, $13.4 \%$ at an afternoon snack at $16: 00$ hours and $34.2 \%$ at dinner at 20:00 hours. Diet composition was $16.7 \%$ protein, $9.8 \%$ fat and $73.5 \%$ carbohydrate at breakfast; $18.8 \%$ protein, $51.2 \%$ fat and $30 \%$ carbohydrate at lunch; $13.4 \%$ protein, $27.7 \%$ fat and $58.9 \%$ carbohydrate at snack time; and $18.9 \%$ protein, $49.8 \%$ fat and $31.3 \%$ carbohydrate at dinner. The average diet composition was $16.9 \%$ protein, $34.6 \%$ fat and $48.5 \%$ carbohydrate. Hourly blood samples were drawn from a central venous catheter for the measurement of glucose, C-peptide and NEFA concentrations.

OGTT A standard $75 \mathrm{~g}$ OGTT was performed in each patient at baseline and after surgery as well as in each volunteer, with blood sampling at $0,30,60,90,120,150$ and $180 \mathrm{~min}$. Insulin sensitivity was computed by the OGTT minimal model [25].

Body composition analysis Body composition was evaluated, on a separate day, by the determination of total body water (TBW) using $0.19 \mathrm{~Bq}{ }^{3} \mathrm{H}_{2} \mathrm{O}$ in $5 \mathrm{ml}$ of saline administered as an intravenous bolus injection [26]. Blood samples were drawn before and $3 \mathrm{~h}$ after the injection. Radioactivity was determined in duplicate on $0.5 \mathrm{ml}$ of plasma in a beta scintillation counter (Model 1600TR; Canberra-Packard, Meriden, CT, USA). Corrections were 
made for non-aqueous hydrogen exchange [27]. Water density at body temperature was assumed to be $0.99371 \mathrm{~kg} / \mathrm{l}$. TBW $(\mathrm{kg})$ was computed as ${ }^{3} \mathrm{H}_{2} \mathrm{O}$ dilution space (litres) $\times$ $0.95 \times 0.99371$. FFM was obtained by dividing TBW by 0.732 [28]. Fat mass was obtained as the difference between body weight and FFM.

All procedures and measurements described for the basal study were repeated in the obese individuals at the follow-up.

$B P D$ This malabsorptive surgical procedure [29] consists of an approximately $60 \%$ distal gastric resection with stapled closure of the duodenal stump. The residual volume of the stomach is about $300 \mathrm{ml}$. The small bowel is transected at $2.5 \mathrm{~m}$ from the ileo-caecal valve, and its distal end is anastomosed to the remaining stomach. The proximal end of the ileum, comprising the remaining small bowel (involved in carrying bilio-pancreatic juice but excluded from food transit), is anastomosed in an end-toside fashion to the bowel, $50 \mathrm{~cm}$ proximal to the ileocaecal valve. Consequently, the total length of absorbing bowel is reduced to $250 \mathrm{~cm}$, the final $50 \mathrm{~cm}$ of which, the so-called common channel, represents the site where ingested food and bilio-pancreatic juices mix.

The study was approved by the Institutional Ethics Committee of the Catholic University of Rome. The nature and purpose of the study were carefully explained to all individuals before they provided their written consent to participate.

Analytical procedures Plasma glucose was measured by the glucose oxidase technique on a Beckman Glucose Analyzer (Beckman, Fullerton, CA, USA). C-peptide was assayed by RIA (MYRIA; Technogenetics, Milan, Italy). Serum NEFA was measured spectrophotometrically.

Mathematical model and parameter estimation The $24 \mathrm{~h}$ ISR was estimated by using a previously proposed mathematical model of glucose-NEFA comodulation [19]. Model equations are reported and briefly explained in the appendix. The model allows the computation of the ISR from the time-course of glucose and NEFA plasma concentrations. To analyse the C-peptide data, the ISR model was complemented by the equations for the whole body C-peptide kinetics. We have used the validated twocompartment model [30, 31], calculating the standard parameters of C-peptide kinetics for each individual as proposed by van Cauter et al. [31].

The ISR model parameters were estimated for each individual by weighted least-squares fitting of plasma C-peptide concentration data [19]. The least-squares index was minimised by means of a constrained LevenbergMarquardt routine of the MATLAB library and the SDs of the estimates of individual parameters were evaluated by the Jackknife method [19]. From the parameter estimates, the $24 \mathrm{~h}$ individual ISR profile was derived. For comparison, the ISR profile was also reconstructed from the plasma C-peptide concentration by the deconvolution method, according to van Cauter et al. [31]. The $\beta$-oxidation rate was computed for each individual by means of Eq. 3 in the appendix.

Statistical analysis All data are expressed as means \pm SE, unless otherwise specified. The Wilcoxon paired-sample test and the ANOVA test for repeated measurements, followed by a Tukey test were used for intragroup and intergroup comparisons, respectively. Two-sided $p<0.05$ was considered significant.

The duration (ranging from 6 months to 10 years before the operation) and the degree of compensation of diabetes $\left(\mathrm{HbA}_{1 \mathrm{c}}\right)$ were used as covariates in a multiple regression analysis where the dependent variable was the change in beta cell glucose sensitivity after BPD.

\section{Results}

A non-significant weight loss $(6.7 \pm 3.3 \mathrm{~kg}[$ mean $\pm \mathrm{SD}])$ was observed 1 week after BPD. The FFM after BPD was $80.9 \pm$ $15.7 \mathrm{~kg}$ and was not significantly different from FFM before BPD. The $24 \mathrm{~h}$ average concentrations of glucose before and after BPD (13.6 \pm 5.6 vs $7.8 \pm 2.6 \mathrm{mmol} / \mathrm{l})$ were significantly different $(p<0.01)$, and the glucose concentration after BPD was not significantly different from that found in controls $(5.2 \pm 1.0 \mathrm{mmol} / \mathrm{l})$. The $24 \mathrm{~h}$ average concentration of C-peptide after BPD $(1.2 \pm 0.7 \mathrm{nmol} / \mathrm{l})$ was significantly $(p<0.05)$ lower than that before BPD $(1.7 \pm 0.9 \mathrm{nmol} / \mathrm{l})$ and did not differ significantly from the average concentration in controls $(0.7 \pm 0.3 \mathrm{nmol} / \mathrm{l})$. The $24 \mathrm{~h}$ average concentrations of NEFA before and after BPD $(0.64 \pm 0.08$ vs $0.65 \pm 0.30 \mathrm{mmol} / \mathrm{l})$ were not significantly different and were larger than in controls $(0.31 \pm 0.08 \mathrm{mmol} / 1, p<0.05)$. The time-course of NEFA plasma level over $24 \mathrm{~h}$ before and after BPD is reported in Fig. 1.

The estimates of model parameters are reported in Table 1. For all individuals, the SD of the individual parameter estimates was consistently $<20 \%$. The parameter $p_{1}$, which represents the $24 \mathrm{~h}$ average beta cell sensitivity to both glucose and NEFA, was doubled 1 week following BPD $(p<0.01)$. Nevertheless, this parameter did not reach the values observed in healthy controls. The parameter $p_{2}$, which is related to the rate of long-chain acyl-CoA (LCCoA) use in the cytosol, recovered completely after BPD, being substantially equal to the values found in controls. Also $p_{3}$, which expresses the efficiency of LC-CoA transport into the mitochondria, where LC-CoAs are 

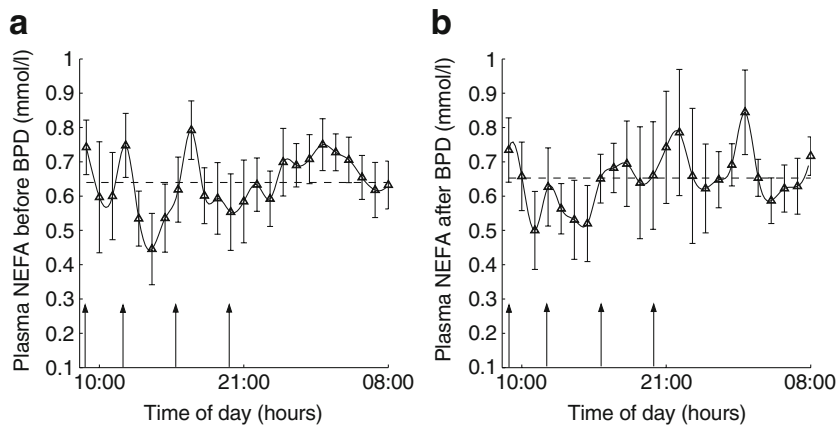

Fig. 1 Time-course over $24 \mathrm{~h}$ of NEFA plasma concentration (means \pm $\mathrm{SE}$ ) in the obese population before (a) and after (b) BPD. The mean value over $24 \mathrm{~h}$ is indicated by the dashed line. The arrows indicate the time of the meals

$\beta$-oxidised, reverted to normality. Thus the ratio $p_{3} / p_{2}$, which represents the balance between LC-CoA $\beta$-oxidation and its use in the cytosol [19], was fully normalised early after the operation. The integral over $24 \mathrm{~h}$ of the insulin secretion rate (ISR; cumulative insulin secretion, $\mathrm{AUC}_{\mathrm{ISR}}$ ) decreased from $277.1 \pm 144.4$ to $198.0 \pm 107.6 \mathrm{nmol} / \mathrm{m}^{2}(p<$ $0.02)$ and did not differ from that found in controls $(135.0 \pm$ $30.0 \mathrm{nmol} / \mathrm{m}^{2}$ ). The amplitude $\delta$ and the initial phase $\varphi$ of the ISR circadian rhythm did not change significantly after BPD. Whereas the amplitude was significantly higher in controls $(p<0.001)$, the phase was not statistically different from before/after BPD. The rate of $\beta$-oxidation in the beta cell was found to be completely normalised after the operation, from $0.032 \pm 0.012 \times 10^{-12}$ to $0.103 \pm 0.031 \times$ $10^{-12} \mathrm{mmol} / \mathrm{min}$ per cell, having assumed a beta cell volume of $1.376 \times 10^{-12} 1$ [32]. For the controls we found $0.098 \pm 0.052 \times 10^{-12} \mathrm{mmol} / \mathrm{min}$ per cell.

Figure $2 \mathrm{a}-\mathrm{c}$ shows the model fitting of the $24 \mathrm{~h}$ C-peptide plasma concentration before and after the operation in a representative diabetic patient. The time-course of the ISR, estimated both by the model and by the deconvolution method, is also reported. The cumulative $24 \mathrm{~h}$ insulin secretion attained the same value when computed by the mathematical model or by the deconvolution. The peaks corresponding to the meals were reduced after the operation, shifting towards the values observed in controls (Fig. 2d,e).

The relationship between the static component of the ISR (denoted as $S$, see Eq. 1 in Appendix) and NEFA concentration is shown in Fig. 3a for controls and type 2 diabetic patients before and after BPD. The curves are plotted at the glucose level $(G)$ indicated, using the parameters $p_{1}, p_{2}$ and $p_{3}$ of Table 1 . The points mark the $24 \mathrm{~h}$ average NEFA/ISR value with the average glucose concentration found in each group of individuals. The variability of the curve with glucose level is shown only for controls. Figure $3 b$ shows the rate of $\beta$-oxidation per cell $(B)$ as a function of plasma glucose concentration, computed by the model (Eq. 3 in appendix) in diabetic patients before and after BPD and in controls. At least to our knowledge, no data are available in the literature on fatty acid oxidation in islets from obese diabetic humans or in healthy individuals. Therefore we plotted in Fig. 3b, as a reference, the values of palmitate oxidation in Zucker lean rat islets, as deduced by the data reported in Nolan et al. [23] assuming that the average beta cellular protein content is $200 \mathrm{fg}$.

The time-courses of glucose and insulin concentration during the OGTT of diabetic patients and controls are shown in Fig. 4. Both the fasting glucose and insulin plasma levels and their values at 120 min were dramatically reduced after BPD. The ADA criteria to define diabetes mellitus (fasting plasma glucose $\geq 7 \mathrm{mmol} / 1$ or an OGTT with the $2 \mathrm{~h}$ postload value $\geq 11.1 \mathrm{mmol} / \mathrm{l}$ ) were no longer fulfilled after the operation, as shown in Fig. 4, so the

Table 1 Population means \pm SD of the parameter estimates for the diabetic patients before and after BPD and for the controls

\begin{tabular}{|c|c|c|c|c|c|c|}
\hline Parameters & $\begin{array}{l}\text { Diabetics } \\
\text { pre-BPD }\end{array}$ & $\begin{array}{l}\text { Diabetics } \\
\text { post-BPD }\end{array}$ & Controls & $\begin{array}{l}\text { Wilcoxon } \\
\text { (pre-BPD vs } \\
\text { post-BPD) }\end{array}$ & $\begin{array}{l}\text { Tukey } \\
\text { (pre-BPD vs } \\
\text { controls) }\end{array}$ & $\begin{array}{l}\text { Tukey } \\
\text { (post-BPD vs } \\
\text { controls) }\end{array}$ \\
\hline $\begin{array}{c}p_{1}(\mathrm{nmol} \mathrm{min}-1 \\
\left.[\mathrm{mmol} / \mathrm{l}]^{-2}\right)\end{array}$ & $0.12 \pm 0.07$ & $0.28 \pm 0.23$ & $1.07 \pm 0.15$ & $p<0.01$ & $p<0.001$ & $p<0.001$ \\
\hline $\begin{array}{c}\delta(\mathrm{nmol} \mathrm{min} \\
\left.[\mathrm{mmol} / \mathrm{l}]^{-2}\right)\end{array}$ & $0.032 \pm 0.031$ & $0.10 \pm 0.12$ & $0.43 \pm 0.17$ & NS & $p<0.001$ & $p<0.001$ \\
\hline$\phi(\mathrm{rad})$ & $6.05 \pm 0.90$ & $4.85 \pm 1.57$ & $5.72 \pm 0.70$ & NS & NS & NS \\
\hline$p_{2}(\mathrm{mmol} / \mathrm{l})$ & $0.76 \pm 0.11$ & $0.14 \pm 0.02$ & $0.13 \pm 0.04$ & $p<0.001$ & $p<0.001$ & NS \\
\hline$p_{3}\left([\mathrm{mmol} / \mathrm{l}]^{2}\right)$ & $3.68 \pm 0.65$ & $8.99 \pm 2.70$ & $7.80 \pm 2.49$ & $p<0.01$ & $p<0.05$ & NS \\
\hline$k_{\mathrm{d}}\left(\mathrm{nmol}[\mathrm{mmol} / \mathrm{l}]^{-1}\right)$ & $0.85 \pm 0.36$ & $1.48 \pm 0.63$ & $1.52 \pm 0.86$ & NS & NS & NS \\
\hline$k\left(\min ^{-1}\right)$ & $0.0023 \pm 0.0009$ & $0.0023 \pm 0.0006$ & $0.0042 \pm 0.0021$ & NS & $p<0.02$ & $p<0.02$ \\
\hline$p_{3} / p_{2}(\mathrm{mmol} / \mathrm{l})$ & $5.03 \pm 1.33$ & $66.48 \pm 20.59$ & $62.18 \pm 21.68$ & $p<0.005$ & $p<0.001$ & NS \\
\hline $\operatorname{AUC}_{\text {ISR }}\left(\mathrm{nmol} / \mathrm{m}^{2}\right)$ & $277.1 \pm 144.4$ & $198.0 \pm 107.6$ & $135.0 \pm 30.0$ & $p<0.02$ & $p<0.005$ & NS \\
\hline $\begin{array}{l}B \times 10^{12}(\mathrm{mmol} / \mathrm{min} \\
\text { per cell })\end{array}$ & $0.032 \pm 0.012$ & $0.103 \pm 0.031$ & $0.098 \pm 0.052$ & $p<0.005$ & $p<0.005$ & NS \\
\hline
\end{tabular}

NS, not significant 


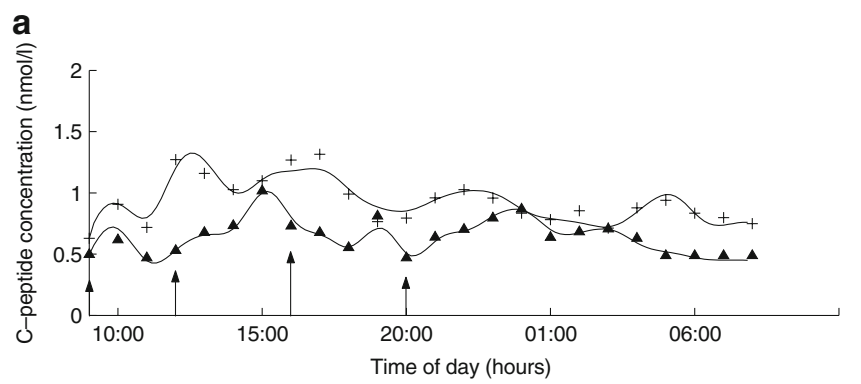

b
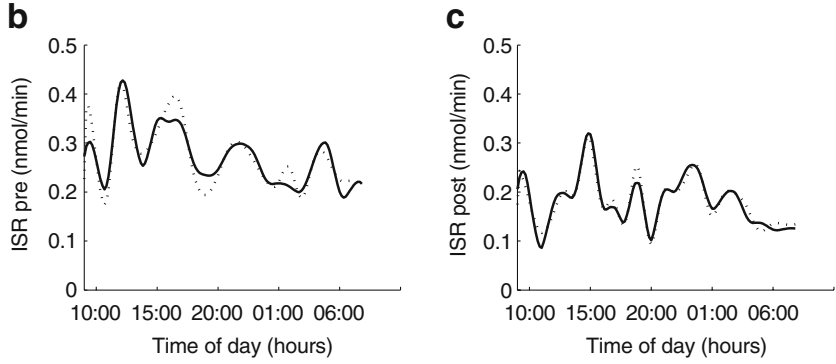

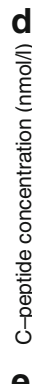

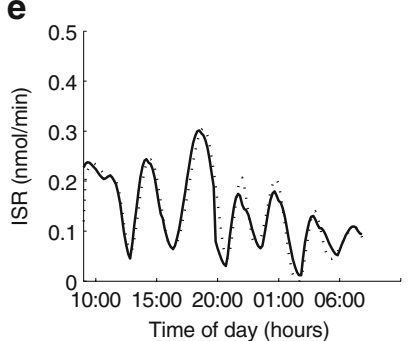

Fig. 2 a 24 h C-peptide plasma concentration data before BPD (+) and 1 week after BPD (triangles) for a representative diabetic patient, with the fitting curves superimposed (solid lines). The $24 \mathrm{~h}$ average $\mathrm{C}$-peptide concentration is significantly reduced $(p<0.001)$. The arrows indicate the time of the meals. b, c ISR time-course as estimated by the model (solid line) and by deconvolution (dotted line) before (left panel) and after (right panel) BPD. The $24 \mathrm{~h}$ average ISR is significantly decreased $(p<0.001)$. d $24 \mathrm{~h}$ C-peptide plasma concentration data for a representative control with the fitting curve superimposed (solid line). e ISR time-course as estimated by the model (solid line) and by deconvolution (dotted line)

diabetes may be considered to be resolved. The estimate of the insulin sensitivity by the OGTT minimal model showed a significant increase 1 week after BPD (from $3.8 \pm 1.2 \times$ $10^{-3}$ to $\left.19.7 \pm 5.3 \times 10^{-3} \mathrm{ml} \mathrm{min}^{-1}[\mathrm{pmol} / 1]^{-1} \mathrm{~kg}^{-1}, p<0.001\right)$ and the value after BPD was not statistically different from controls $\left(18.9 \pm 5.9 \times 10^{-3} \mathrm{ml} \mathrm{min}^{-1}[\mathrm{pmol} / 1]^{-1} \mathrm{~kg}^{-1}\right)$.

The improvement in the beta cell function, measured by the difference $\Delta p_{1}=p_{1, \text { postBPD }}-p_{1, \text { preBPD }}$, significantly $(p<0.0001)$ correlated with both the time interval between
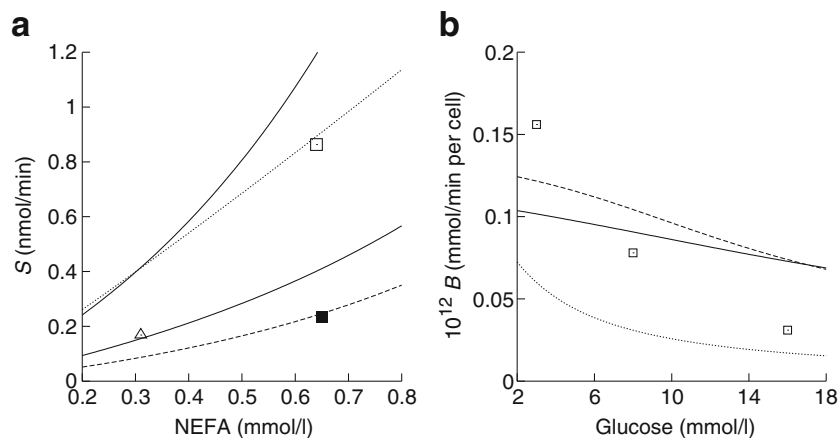

Fig. 3 a Model-computed static component of the ISR $(S)$ as a function of NEFA concentration for controls $(G=8 \mathrm{mmol} / \mathrm{l}$, upper solid line and $G=5 \mathrm{mmol} / \mathrm{l}$, lower solid line) and for type 2 diabetic patients before BPD ( $G=14 \mathrm{mmol} / \mathrm{l}$, dotted line) and after BPD ( $G=8 \mathrm{mmol} / \mathrm{l}$, dashed line). The points mark the $24 \mathrm{~h}$ average NEFA/ISR value with the average glucose concentration in controls (triangle) and diabetic patients before (white square) and after BPD (black square). The variability of the curve with glucose is shown only for controls. b Model-computed $\beta$-oxidation rate $(B)$ as a function of glucose concentration at the NEFA levels corresponding to the $24 \mathrm{~h}$ average values reported in the results: controls $(F=0.31 \mathrm{mmol} / \mathrm{l}$, solid line); pre-BPD diabetic patients $(F=0.64$ $\mathrm{mmol} / \mathrm{l}$, dotted line); post-BPD diabetic patients $(F=0.65 \mathrm{mmol} / \mathrm{l}$, dashed line). Data for palmitate oxidation rate in lean Zucker rat islets (squares) are derived from Fig. 3a in Nolan et al. [23] as explained in the text

diagnosis of diabetes and surgery $(y=-0.0307 x+0.2812$, $\left.R^{2}=0.88\right)$ and the $\mathrm{HbA}_{1 \mathrm{c}}$ values averaged over the last 3 months preceding BPD $\left(y=-0.0458 x+0.5842, R^{2}=0.78\right)$. In a multivariate analysis, where the dependent variable was $\Delta p_{1}$ and the independent variables were $\mathrm{HbA}_{1 \mathrm{c}}$ and diabetes duration, the best predictor of the beta cell function improvement was the duration of diabetes ( $\beta$ coefficient $-0.667, p=0.023$; adjusted $R^{2}$ of the model $=0.89$ ). The longer the duration of diabetes, the lower was the recovery of beta cell function. a

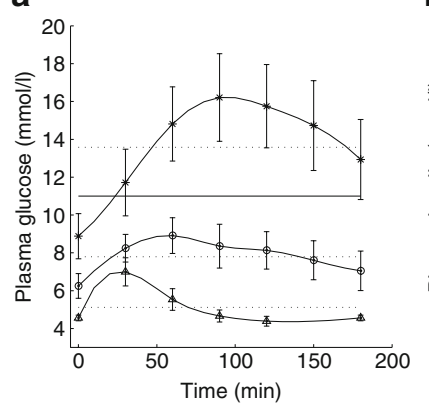

b

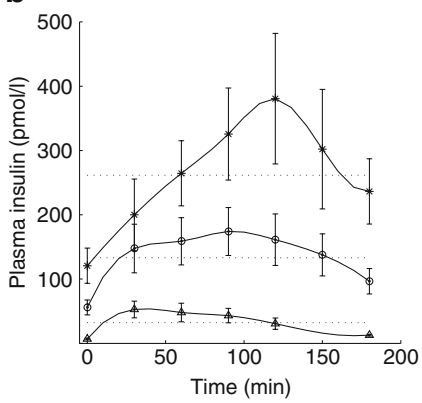

Fig. 4 Time-course of plasma glucose (a) and plasma insulin (b) during the OGTT. Asterisks, before BPD; circles, 1 week after BPD; triangles, controls. Data are expressed as mean \pm SE (glucose: $p<0.003$ before vs after, NS after vs controls; insulin: $p<0.03$ before vs after, NS after vs controls). In the plasma glucose panel (a), the solid line represents the level indicated by $\mathrm{ADA}$ for diagnosis of diabetes 


\section{Discussion}

The major results of the present study may be stated as follows:

1. In diabetic patients who underwent malabsorptive bariatric surgery, the beta cell glucose/NEFA sensitivity was doubled early after the operation, before a significant weight loss was achieved.

2. The shorter the time interval between diagnosis of type 2 diabetes and bariatric operation and the lower the severity of diabetes, the better was the recovery of beta cell function.

3. Fatty acid oxidation in the beta cell, as calculated by the mathematical model, was fully normalised after BPD, suggesting that the impairment of pancreatic fatty acid $\beta$-oxidation is a reversible phenomenon.

4. Insulin secretion was reduced mainly as a consequence of the normalisation of insulin sensitivity. Circulating NEFA was indeed slightly, although not significantly, increased after BPD, probably as a consequence of the increased fat mobilisation by hormone-sensitive lipase, which is activated when the circulating insulin level drops. The lack of a significant increase in NEFA concentration may be attributable to a higher insulin sensitivity of adipose tissue, which attenuates the potential rise in NEFA.

Points 1-4 are discussed in detail in the following.

Beta cell glucose/NEFA sensitivity One of the first pieces of evidence of diabetes resolution after bariatric surgery was reported by Pories et al. [33]. Although the surgical technique used in that study was the gastric bypass, whereas BPD was used in the present study, in our series also diabetes was reversed early after the operation when body weight was quite unchanged.

Insulin sensitivity exerts a modulating effect on the beta cell function, so that beta cells are initially able to compensate for insulin resistance, thus maintaining glucose homeostasis. In fact, insulin sensitivity and beta cell function are inversely related, whereby the product of these two parameters is a constant referred to as the disposition index [34]. But insulin hypersecretion is no longer able to fully compensate for increasing insulin resistance when beta cell function is impaired, so that type 2 diabetes mellitus develops [35-40]. Individuals with impaired glucose tolerance and overt type 2 diabetes are characterised by moderate to severe insulin resistance [40, 41]. For instance, Haffner et al. [42] reported that insulin resistance was present in $>85 \%$ of a cohort of diabetic individuals. It is interesting to note that Ferrannini et al. [41] have shown that a halving of beta cell glucose sensitivity or a halving of insulin sensitivity predicts a similar rise in the $2 \mathrm{~h}$ glycaemia after glucose challenge as well as in the fasting plasma glucose levels, suggesting that either the beta cell glucose sensitivity or the insulin resistance can equally contribute to hyperglycaemia in type 2 diabetic patients.

In our series, a reduction of insulin secretion was found after BPD in all individuals whereas the insulin sensitivity was significantly increased, suggesting that the improvement of insulin sensitivity may induce a corresponding improvement in beta cell glucose/NEFA sensitivity.

Relationship between diabetes duration and beta cell function recovery The effect of bariatric surgery in terms of recovery of beta cell function $\left(\Delta p_{1}\right)$ was maximal in those individuals whose diabetes was diagnosed shortly before the operation, while the effect decreased linearly with the increase of diabetes duration. The UKPDS data [43] clearly indicate that there is a progressive deterioration of pancreatic beta cell function as type 2 diabetes progresses. In fact, type 2 diabetic patients at diagnosis had about $50 \%$ reduction in pancreatic beta cell function and were insulin resistant, whereas over time there was a reduction (about $4 \% /$ year) in the beta cell function regardless of treatment, without change in insulin resistance.

In agreement with our results Schauer et al. [44] found, in a cohort of 1,160 patients who underwent laparoscopic Roux-en-Y gastric bypass, that the factors that negatively correlated with type 2 diabetes mellitus resolution included the preoperative duration of diabetes, high levels of $\mathrm{HbA}_{1 \mathrm{c}}$ and insulin therapy, which are all measures of diabetes severity. In contrast, the weight loss was positively associated with diabetes resolution. Our data are not affected by the weight loss variable, since our patients were studied very early after the operation when no significant weight loss was attained.

On the basis of the present observations, it may be hypothesised that in patients with long-standing type 2 diabetes the defects in beta cell mass predominate, whereas the patients with a short duration of diabetes primarily exhibit an impairment in beta cell function.

Beta cell fatty acid oxidation A $\beta$-oxidation impairment in the beta cells has been described by Frigerio et al. [45]. The anti-epileptic drug topiramate exerts a protective effect against INS-1E beta cell lipotoxicity induced by prolonged exposure to high levels of fatty acids, by enhancing the cellular capacity of lipid clearance. In fact, this drug enhances the $\beta$-oxidation rate, suggesting that a protective mechanism against lipotoxicity could be the inhibition of lipid accumulation in the cytoplasm through increased fatty acid oxidation. 
Furthermore, fa/fa rat islets, a useful replica of the human phenotype of adipogenic type 2 diabetes, exhibit a markedly increased lipogenic capacity and a decreased oxidative capacity [46]; unused NEFA in islets are esterified and over time an excessive quantity of triacyglycerol is deposited [46].

Our observation that fatty acid oxidation rate in beta cells is normalised a few days after BPD suggests that the impairment of fatty acid oxidation is reversible and that it is not related to the fatty acid overloading of beta cells. In fact, circulating NEFA levels were not statistically changed from before BPD, when their oxidation rate was calculated to be three times lower than in healthy controls.

At least to our knowledge this is the first evidence of a defect in beta cell fatty acid oxidation in type 2 diabetes in humans. This defect is completely reversed shortly after BPD even before complete normalisation of beta cell glucose sensitivity. It is likely that this prompt reversibility might depend on the removal of some competitive inhibitory action exerted on carnitine palmitoyltransferase 1 (CPT-1).

Insulin secretion It has been reported that in type 2 diabetic patients the insulin pulses related to meals are decreased in amplitude and disorganised in their temporal pattern [47, 48] and that, in most diabetic patients, these abnormal patterns did not improve with weight loss [49].

In our post-BPD patients, although insulin secretion was reduced, it was still sufficient to provide a normalisation of the insulin-dependent glucose disposal. This effect occurred in spite of the non-significant reduction in circulating NEFA levels, suggesting that other mechanisms should intervene. In particular we hypothesise that insulin sensitivity normalisation may be the first to occur and that, secondarily, the need for insulin secretion diminishes.

\section{Conclusions}

Malabsorptive bariatric surgery in type 2 diabetic patients restores $\beta$-oxidation in pancreatic beta cells, doubles the glucose-NEFA sensitivity and reverts to normality the diabetic condition. Since circulating NEFA levels (which together with glucose concentration determine the ISR) do not decrease significantly, it is likely that it is the normalisation of insulin sensitivity that causes the reduction of insulin secretion. A fivefold increase of insulin sensitivity, as was observed in our study population, is much higher than that usually obtained by insulin sensitising agents, and it is independent of weight changes. Therefore, it is conceivable that the altered intestinal physiology produced by the surgical operation could be the causative factor of these findings. In particular, the exclusion of part of the small bowel from food transit might act to avoid local production of factor(s) worsening insulin sensitivity.

We stress that the results of the present study cannot be extended to all type 2 diabetic patients since they derive from a specific category of patients where the insulin secretion is still high enough in spite of frank diabetes mellitus.

Duality of interest The authors declare that there is no duality of interest associated with this manuscript.

\section{Appendix}

Mathematical model

We describe here in a synthetic form the mathematical model of NEFA-glucose comodulation of beta cell insulin secretion [19].

As in other mathematical models of glucose-stimulated insulin secretion [20,50], the ISR is given by the sum of a static and a dynamic component. The static component is modelled here according to the view that a dual signalling pathway that involves both glucose and LC-CoA regulates the stimulation of insulin secretion [22] (see Fig. 5). The kinetics of LC-CoA formation from exogenous NEFA is represented by a single rate constant $k$. Cytosolic LC-CoA has two possible fates: bind to CPT-1 and be transported into mitochondria to undergo $\beta$-oxidation, or be enrolled in diacylglycerol (DAG) synthesis and enhance the ISR, possibly via activation of protein kinase C. A key aspect of the model is that it describes in a very simplified way the inhibitory action of glucose (via malonyl-CoA) on the binding of LC-CoA to CPT-1 and thus on the rate of LC$\mathrm{CoA}$ transport into mitochondria.

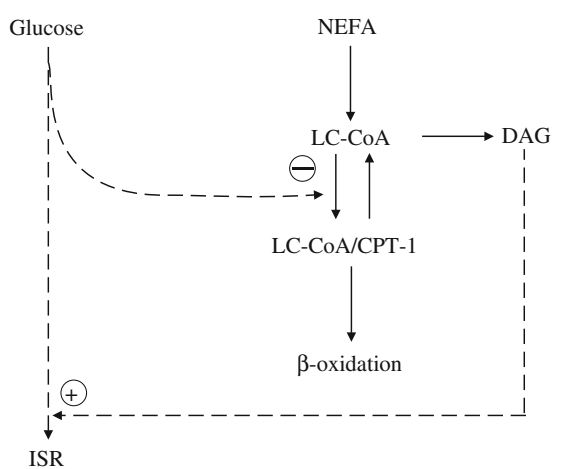

Fig. 5 Schematic representation of the dual pathway involved in the stimulation of insulin secretion by glucose and NEFA. Glucose, via malonyl-CoA, inhibits the binding of LC-CoA to CPT-1 and its transport into mitochondria. The dashed arrows indicate the control actions considered in the model, with ' + ' denoting potentiation and '-' inhibition 
The following equation for the static ISR component $S$ (expressed in nmol/min) has been obtained [19]:

$$
\begin{aligned}
S= & \frac{p_{1}}{2} \\
& \times\left[-\left(p_{2}+\frac{p_{3}}{G}-F\right)+\sqrt{\left(p_{2}+\frac{p_{3}}{G}-F\right)^{2}+4 p_{2} F}\right] G
\end{aligned}
$$

where $G$ and $F$ are the glucose and NEFA concentration respectively, the coefficient $p_{1}$ is the beta cell sensitivity to both glucose and NEFA, $p_{2}$ is related to the rate of LC-CoA use in the cytosol, and $p_{3}$ expresses the efficiency of LCCoA transport into mitochondria where LC-CoAs are $\beta$-oxidised. The term in square brackets in Eq. 1 is a sort of 'potentiation factor' that accounts for the action of fatty acids on insulin secretion and the influence of glucose on fatty acid metabolism. By adding the dynamic component to the static component, we obtain the expression for the ISR:

$\mathrm{ISR}=\left\{\begin{array}{cc}S+k_{\mathrm{d}} \mathrm{d} G / \mathrm{d} t, & \mathrm{~d} G / \mathrm{d} t>0 \\ S, & \mathrm{~d} G / \mathrm{d} t<0\end{array}\right.$

Because the parameter $p_{1}$ was found to change with the time during the $24 \mathrm{~h}$ meal test [19], we have added to $p_{1}$ a circadian oscillation [20]. Thus the glucose/NEFA sensitivity coefficient is expressed as $p_{1}+\delta \sin (2 \pi t / T+\varphi)$, where $p_{1}$ is the average value over the $24 \mathrm{~h}, \delta$ is the amplitude of the oscillation, $T$ is the period equal to $24 \mathrm{~h}$, and $\varphi$ is the phase at the initial time ( $t=0$ taken at 08:00 hours). The ISR model has the following unknown parameters: $k, p_{1}, p_{2}, p_{3}$, $\delta, \varphi, k_{\mathrm{d}}$, to be estimated from the data.

In the hypothesis that the LC-CoA transported into the mitochondria is completely $\beta$-oxidised, the rate of $\beta$-oxidation $B$ (expressed as $\mathrm{mmol} / \mathrm{min}$ per cell) can be determined as the difference between the NEFA influx into the beta cell and the rate of LC-CoA use in the cytosol. This leads to the expression:

$B=\frac{k}{2}\left[p_{2}+\frac{p_{3}}{G}+F-\sqrt{\left(p_{2}+\frac{p_{3}}{G}-F\right)^{2}+4 p_{2} F}\right] V$

where $V$ is the volume of the beta cell. It may be seen that $B$ decreases with the increase of the glucose concentration $G$.

\section{References}

1. Rebuffe-Scrive M, Anderson B, Olbe L, Bjorntorp P (1990) Metabolism of adipose tissue in intraabdominal depots in severely obese men and women. Metabolism 39:1021-1025

2. Boden G (1997) Role of fatty acids in the pathogenesis of insulin resistance and NIDDM. Diabetes 46:3-10
3. Cusi K, DeFronzo RA (2001) Non-insulin dependent diabetes mellitus. In: Jefferson LS, Cherrington AD (eds) The endocrine pancreas and regulation of metabolism, handbook of physiology. Oxford University Press, New York, pp 1115-1168

4. Kelley D, Mandarino L (2000) Fuel selection in human skeletal muscle in insulin resistance. A reexamination. Diabetes 49:677683

5. Magnan C, Cruciani C, Clement L et al (2001) Glucose-induced insulin hypersecretion in lipid-infused healthy subjects is associated with a decrease in plasma norepinephrine concentration and urinary excretion. J Clin Endocrinol Metab 86:4901-4907

6. Unger RH (1995) Lipotoxicity in the pathogenesis of obesitydependent NIDDM: genetic and clinical implications. Diabetes 44:863-869

7. Gulli G, Ferrannini E, Stern M, Haffner S, DeFronzo RA (1992) The metabolic profile of NIDDM is fully established in glucosetolerant offspring of two Mexican-American NIDDM parents. Diabetes 41:1575-1586

8. Lillioja S, Mott D, Spraul M et al (1993) Insulin resistance and insulin secretory dysfunction as precursors of non-insulin-dependent diabetes mellitus. N Engl J Med 329:1988-1992

9. Vauhkonen I, Niskanen L, Vanninen E, Kainulainen S, Uusitupa M, Laakso M (1997) Defects in insulin secretion and insulin action in non-insulin-dependent diabetes mellitus are inherited. J Clin Invest 100:86-96

10. Nolan CJ, Madiraju MSR, Delghingaro-Augusto V, Peyot M-L, Prentki M (2006) Fatty acid signaling in the beta-cell and insulin secretion. Diabetes 55:S16-S23

11. Kashyap S, Belfort R, Gastaldelli A et al (2003) A sustained increase in plasma free fatty acids impairs insulin secretion in nondiabetic subjects genetically predisposed to type 2 diabetes. Diabetes 52:2461-2474

12. Cusi K, Kashyap S, Gastaldelli A, Bajaj M, Cersosimo E (2007) Effects on insulin secretion and action of a 48-hour reduction of plasma FFA with acipimox in non-diabetic subjects genetically predisposed to type 2 diabetes. Am J Physiol Endocrinol Metab 292:E1775-E1781

13. Mingrone G, Manco M, Granato L et al (2005) Leptin pulsatility in formerly obese women. FASEB J 19:1380-1382

14. Vettor R, Mingrone G, Manco M et al (2003) Reduced expression of uncoupling proteins- 2 and -3 in adipose tissue in post-obese patients submitted to biliopancreatic diversion. Eur J Endocrinol 148:543-550

15. Greco AV, Mingrone G, Vettor R et al (2002) Lowering of circulating free-fatty acids levels and reduced expression of leptin in white adipose tissue in postobesity status. J Investig Med 50:207-213

16. Mingrone G, De Gaetano A, Greco AV et al (1997) Reversibility of insulin resistance in obese diabetic patients: role of plasma lipids. Diabetologia 40:599-605

17. Camastra S, Manco M, Mari A et al (2007) Beta-cell function in severely obese type 2 diabetic patients: long-term effects of bariatric surgery. Diabetes Care 30:1002-1004

18. Guidone C, Manco M, Valera-Mora E et al (2006) Mechanisms of recovery from type 2 diabetes after malabsorptive bariatric surgery. Diabetes 55:2025-2031

19. Salinari S, Bertuzzi A, Manco M, Mingrone G (2007) NEFAglucose comodulation model of beta-cell insulin secretion in 24-h multiple-meal test. Am J Physiol Endocrinol Metab 292: E1890-E1898

20. Mari A, Camastra S, Toschi E et al (2001) A model for glucose control of insulin secretion in $24 \mathrm{~h}$ of free living. Diabetes 50 (Suppl 1):S164-S168

21. Mari A, Schimtz O, Gastaldelli A, Oestergaard T, Nyholm B, Ferrannini E (2002) Meal and oral glucose tests for assessment of 
beta-cell function: modeling analysis in normal subjects. Am $\mathrm{J}$ Physiol Endocrinol Metab 283:E1159-E1166

22. Prentki M, Corkey BE (1996) Are the beta-cell signaling molecules malonyl-CoA and cytosolic long-chain acyl-CoA implicated in multiple tissue defects of obesity and NIDDM? Diabetes 45:273-283

23. Nolan CJ, Leahy JL, Delghingaro-Augusto V et al (2006) Beta-cell compensation for insulin resistance in Zucker fatty rats: increased lipolysis and fatty acid signalling. Diabetologia 49:2120-2130

24. Report of the Expert Committee on the Diagnosis and Classification of Diabetes Mellitus (2003) Diabetes Care 26:S5-S20

25. Dalla Man C, Yarasheski KE, Caumo A et al (2005) Insulin sensitivity by oral glucose minimal models: validation against clamp. Am J Physiol Endocrinol Metab 289:E954-E959

26. Siri WE (1961) Body composition from fluid spaces and density: analysis of methods. In: Brozek J, Henschel A (eds) Techniques of measuring body composition. National Academy of Sciences, National Research Council, Washington, DC, pp 107-141

27. Culebras JM, Moore FD (1977) Total body water and the exchangeable hydrogen. I. Theoretical calculation of nonaqueous exchangeable hydrogen in man. Am J Physiol Regul Integr Comp Physiol 232:R54-R59

28. Sheng HP, Huggins RA (1979) A review of body composition studies with emphasis on total body water and fat. Am J Clin Nutr 32:630-647

29. Scopinaro N, Gianetta E, Civalleri D, Bonalumi U, Bachi V (1979) Bilio-pancreatic bypass for obesity. II. Initial experience in man. Br J Surg 66:618-620

30. Polonsky KS, Licinio-Paixao J, Given BD, Pugh W, Rue P, Frank B (1986) Use of biosynthetic human C-peptide in the measurement of insulin secretion rates in normal volunteers and in type I diabetic patients. J Clin Invest 77:98-105

31. van Cauter E, Mestrez F, Sturis J, Polonsky KS (1992) Estimation of insulin secretion rates from C-peptide levels. Comparison of individual and standard kinetic parameters for C-peptide clearance. Diabetes 41:368-377

32. Olofsson CS, Göpel SO, Barg S et al (2002) Fast insulin secretion reflects exocytosis of docked granules in mouse pancreatic betacells. Pflügers Archiv 444:43-51

33. Pories WJ, Swanson M, MacDonald KG et al (1995) Who would have thought it? An operation proves to be the most effective therapy for adult onset diabetes mellitus. Ann Surg 222:339-352

34. Bergman RN (1989) Toward physiological understanding of glucose tolerance. Minimal-model approach. Lilly lecture. Diabetes $38: 1512-1527$

35. Stumvoll M, Tataranni A, Stefan N, Vozarova B, Bogardus C (2003) Glucose allostasis. Diabetes 52:903-909

36. Pratley RE, Weyer C (2001) The role of impaired early insulin secretion in the pathogenesis of type II diabetes mellitus. Diabetologia 44:929-945
37. Weyer C, Bogardus C, Mott DM, Pratley RE (1999) The natural history of insulin secretory dysfunction and insulin resistance in the pathogenesis of type 2 diabetes mellitus. J Clin Invest 104:787-794

38. Gerich JE (2003) Contributions of insulin resistance and insulinsecretory defects to the pathogenesis of type 2 diabetes mellitus. Mayo Clin Proc 78:447-456

39. Elbein SC, Hasstedt SJ, Wegner K, Kahn SE (1999) Heritability of pancreatic beta-cell function among nondiabetic members of Caucasian familial type 2 diabetic kindreds. J Clin Endocrinol Metab 84:1398-1403

40. Ferrannini E, Natali A, Bell P, Cavallo-Perin P, Lalic N, Mingrone G (1997) Insulin resistance and hypersecretion in obesity. J Clin Invest 100:1166-1173

41. Ferrannini E, Gastaldelli A, Miyazaki Y et al (2003) Predominant role of reduced beta-cell sensitivity to glucose over insulin resistance in impaired glucose tolerance. Diabetologia 46:1211-1219

42. Haffner S, Howard G, Mayer E et al (1997) Insulin sensitivity and acute insulin response in African-Americans, non-Hispanic whites, and Hispanics with NIDDM: the Insulin Resistance Atherosclerosis Study. Diabetes 47:63-69

43. UK Prospective Diabetes Study Group (1995) Prospective diabetes study 16: overview of 6 years' therapy of type II diabetes: a progressive disease. Diabetes 44:1249-1258

44. Schauer PR, Burguera B, Ikramuddin S et al (2003) Effect of laparoscopic Roux-en Y gastric bypass on type 2 diabetes mellitus. Ann Surg 238:467-484

45. Frigerio F, Chaffard G, Berwaer M, Maechler P (2006) The antiepileptic drug topiramate preserves metabolism-secretion coupling in insulin secreting cells chronically exposed to the fatty acid oleate. Biochem Pharmacol 72:965-973

46. Lee Y, Hirose H, Zhou Y-T, Esser V, McGarry JD, Unger RH (1997) Increased lipogenic capacity of the islets of obese rats: a role in the pathogenesis of NIDDM. Diabetes 46:408-413

47. Polonsky KS, Given BD, Hirsch LJ et al (1988) Abnormal patterns of insulin secretion in non-insulin-dependent diabetes mellitus. N Engl J Med 318:1231-1239

48. Calles-Escandon J, Jaspan J, Robbins DC (1989) Postprandial oscillatory patterns of blood glucose and insulin in NIDDM. Abnormal diurnal insulin secretion patterns and glucose homeostasis independent of obesity. Diabetes Care 12:709-714

49. Gumbiner B, van Cauter E, Beltz WF et al (1996) Abnormalities of insulin pulsatility and glucose oscillations during meals in obese noninsulin-dependent diabetic patients: effect of weight reduction. J Clin Endocrinol Metab 81:2061-2068

50. Toffolo G, Breda E, Cavaghan MK, Ehrmann DA, Polonsky KS, Cobelli C (2001) Quantitative indexes of beta-cell function during graded up and down glucose infusion from C-peptide minimal models. Am J Physiol Endocrinol Metab 280:E2-E10 